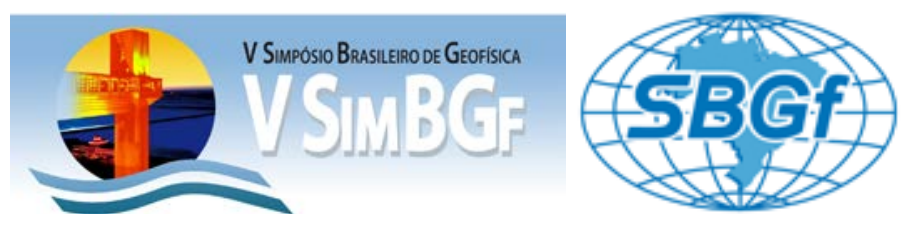

\title{
Evidências de magmatismo e Intrusões ígneas na seção Pré-cone Bacia da Foz do Amazonas.
}

\author{
Raphael Victor Aleixo Vasconcellos ${ }^{1}$, Egberto Pereira ${ }^{2}$, Renato L. Silveira ${ }^{1}$, Elaine M. \\ Loureiro $^{1}$ e Zaque Alves ${ }^{3}$
}

\author{
${ }^{1}$ Especialista em Geologia e Geofísica da Agência Nacional do Petróleo, Gás Natural e Biocombústiveis. \\ 2Professor da Universidade Estadual do Rio de Janeiro \\ ${ }^{3}$ Consultor da IHS
}

Este texto foi preparado para a apresentação no V Simpósio Brasileiro de Geofísica, Salvador, 27a 29 de novembro de 2012. Seu conteúdo foi revisado pelo Comitê Técnico do VSimBGt, mas não necessariamente representa a opinião da SBGf ou de seus associados. É proibida a reprodução total ou parcial deste material para propósitos comerciais sem prévia autorização da SBGf.

\section{Resumo}

A Bacia da Foz do Amazonas localiza-se no extremo noroeste da plataforma continental brasileira, mais precisamente na margem equatorial (Figura 1). Esta margem se distingue da margem leste brasileira, principalmente, pela existência de esforços transtensivos que culminaram com a criação de falhas transformantes de direção E-W, que levaram a criação de bacias do tipo pull apart. Essas estruturas profundas serviram de condutos para o magmatismo descrito neste trabalho. Esta bacia, ainda se difere das demais bacias brasileiras, devido à existência de um expressivo pacote sedimentar depositado nos últimos $11 \mathrm{Ma}$., que pode chegar a mais de 10.000 metros de sedimentos, denominada Cone Amazônico. Dessa forma, a mesma ainda apresenta um arcabouço estratigráfico pouco compreendido.

\section{Introdução}

Recentes descobertas no Oeste africano de campos como Tweneboa e Jubilee em turbiditos do Campaniano/Turoniano despertaram a busca por análogos na margem equatorial brasileira. Há também descobertas comprovadas na Guiana Francesa (Zaedyus) em turbiditos análogos aos da margem Oeste africana, abrindo assim a possibilidade de se encontrar hidrocarbonetos em turbiditos, de mesma idade, na margem equatorial brasileira.

Esta margem, assim como a própria Bacia da Foz do Amazonas, é considerada uma região carente de estudos. Assim, este trabalho pretende contribuir para um maior conhecimento geológico desta área, que talvez represente a região mais desconhecida e complexa de nossa plataforma continental. Vasconcellos, (2012) realizou observações para as formações mais antigas que o Cone Amazônico (de 11 Ma.) como, por exemplo, a influência de intrusões ígneas nas formações Caciporé/Codó posicionadas na sequência rifte, atingindo até mesmo a Formação Limoeiro (sequência pós-rifte), bem como a presença de falhas normais que atingiram a plataforma carbonática do Amapá, relacionadas à feição ígnea mapeada. Deste modo, fica claro que a feição ígnea descrita não é restrita à fase pré-rifte (Fm. Calçoene) como já estabelecido e descrito por outros trabalhos (Brandão e Feijó, 1994 e Figueiredo et al. 2007) conhecida na bacia. No entanto, amostras datadas deste material magmático indicam uma idade Triássica (cerca de $200 \mathrm{Ma}$ ). Aparentemente, há pulsos no centro do corpo ígneo que podem ser mais novos do que 200 Ma., relacionados à reativações de falhas. Tal feição ígnea pode ter sido o substrato para a formação de uma plataforma mista (intercalação de siliciclásticos com carbonatos), que na bacia estaria representada pela Formação Limoeiro.

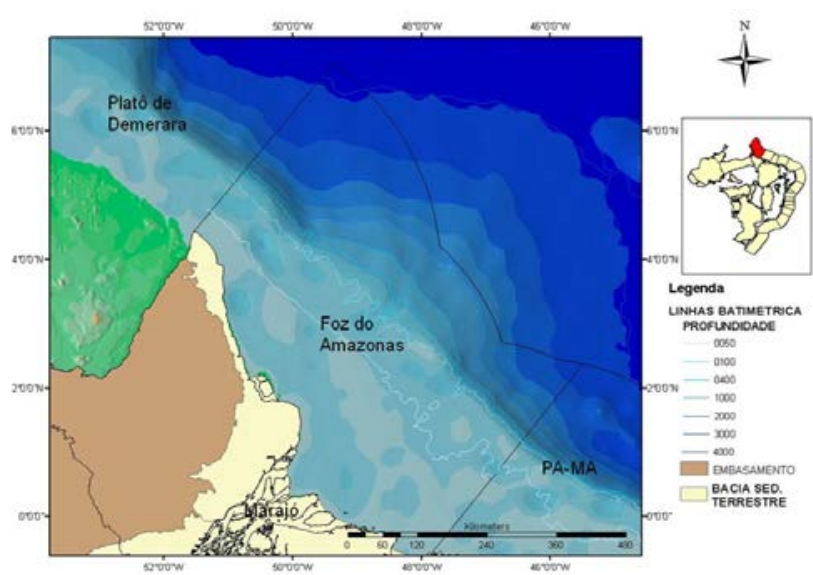

Figura 1 - Localização da Bacia da Foz do Amazonas.

\section{Metodologia}

Para esta análise foram utilizados dados sísmicos em tempo e poços. A partir da integração e análise chegouse a conclusão da existência das feições ígneas de composição basáltica toleítica. Além disso, foram utilizados dados públicos do levantamento magnetométrico EMAG2 (Figura 2), que se encontram disponibilizados no site http://geomag.org/models/emag2.html. Esses dados foram utilizados para a confirmação da existência de intrusões ígneas na linha strike 0047-1067, interpretada utilizando o software Kingdon®. (Figura 3). 


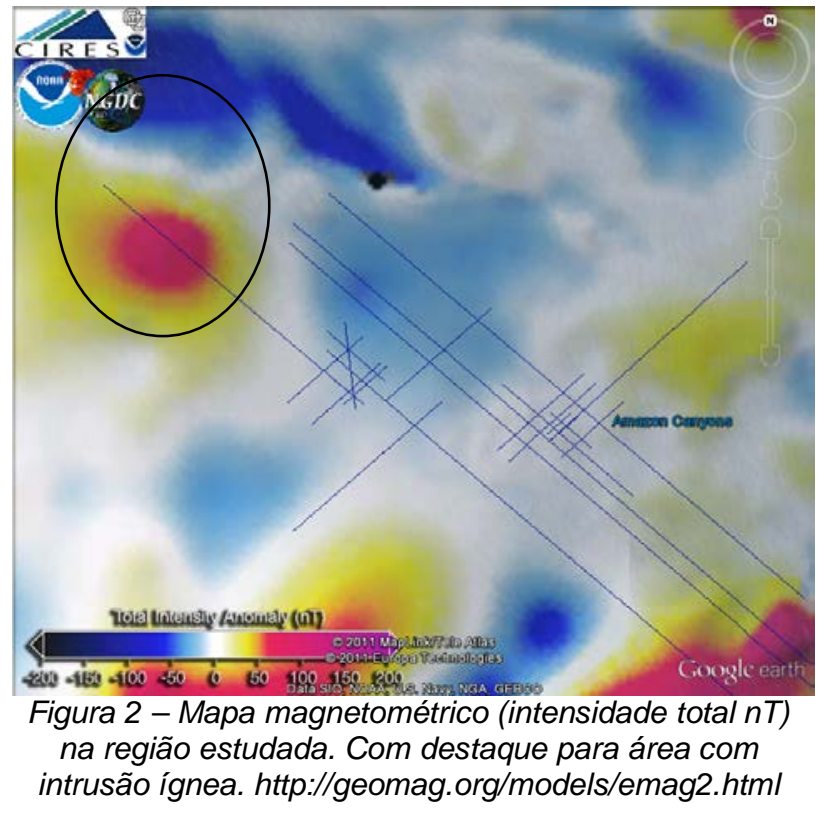

\section{Resultados}

Na linha strike 0047-1067 foi possível reconstruir uma parte significativa da história evolutiva da Bacia da Foz do Amazonas (Figura 3). Interpretou-se a partir da análise de refletores uma estrutura ígnea deformando a Formação Caciporé (sequência Rifte) e, possivelmente, a Formação Limoeiro (sequência Pós-rifte). Aparentemente, esta feição ígnea intrudiu em sedimentos da Formação Calçoene. Na carta estratigráfica da bacia (Figueiredo et al.,2007) é indicada a existência de intercalações ígneas, somente na Formação Calçoene de idade pré-rifte (Juro-Triássica), No entanto, a análise da linha deixa evidências de que este material ígneo pode estar intercalado com sedimentos, até mesmo, da Formação Limoeiro (fase pós-rifte) ou, no mínimo, afetado a mesma através de falhas. Foi utilizado um mapa magnetométrico total (Figura 2) para confirmação da existência da feição ígnea, descartando-se a possibilidade de eventuais diápiros de argila, sendo que este último é muito comum no domínio compressional da tectônica gravitacional da bacia.

O estudo desta linha sugere também a existência de uma drenagem que corria de noroeste para sudeste, perpendicular ao sistema fluvial atual (indicado por seta amarela). Tal feição progradacional de geometria sigmoidal refere-se à plataforma mista da Formação Limoeiro do Cretáceo Superior, formada pela deposição predominante de rochas siliciclásticas e intercalações de carbonatos.

A região a NW da seção sísmica 0047-1067 apresenta uma sedimentação da Fm. Caciporé contemporânea ao evento magmático gerando feições de crescimento em função da presença de falhas de crescimento e espessamento de seção em depocentro localizado.
Aparentemente, o material ígneo basáltico intrudiu os sedimentos até pelo menos a deposição da Formação Limoeiro, de forma muito semelhante às feições de guyots, que ocorrem atualmente na Bacia do Ceará. Este fato não seria uma surpresa, pois falhas transformantes afetam a Bacia da Foz do Amazonas assim como toda margem Equatorial Brasileira e são decorrentes de esforços distensionais, que culminaram com a separação dos continentes sul-americano e africano, estando ativas até o presente momento.

É possível interpretar uma primeira fase associada à deposição dos sedimentos pré-rifte com refletores plano-paralelos, porém esta estrutura ígnea já se encontrava em atividade criando assim depósitos vulcano-clásticos característicos da Formação Calçoene. A Figura 4 apresenta um detalhe da área de ocorrência das rochas ígneas, onde se pôde registrar a ocorrência de diversos eventos magmáticos, muito semelhante a uma grande cratera.

A deposição da sequência rifte, envolvendo as formações Caciporé e Codó (Figueiredo et al., 2007) inicia-se, principalmente, em grabens profundos e desenvolvidos como, por exemplo, aquela observada na área a NW da linha sísmica. Em seguida, inicia-se a deposição de sedimentos de uma plataforma mista descrita inclusive em amostra de calhas e testemunhos, tratando-se de sedimentos clásticos finos intercalados com níveis de carbonatos denominados Formação Limoeiro.

Aparentemente, o início da deposição da plataforma carbonática do Amapá coincide com o resfriamento da feição ígnea, pois na linha sísmica 00471067 é possível identificar que o material ígneo não reestrutura a mesma, embora haja algumas falhas que podem estar possivelmente relacionadas à intumescência desta intrusão ígnea de grandes proporções. Em suma, as análises dos dados sísmicos indicam que quando houve a deposição da plataforma carbonática, o material ígneo ainda se encontrava ativo. Feição semelhante a um atol deve ter sido formada sobre esta feição ígnea, com a fixação inicialmente de uma plataforma mista e posteriormente de uma plataforma carbonática. Observase uma subsidência diferenciada, onde na região à NW (esquerda) da linha há pouco espaço para deposição e a SE da linha (direita) há uma maior criação de espaço, onde ocorre deposição de corpos de geometria sigmoidal, referentes a uma progradação de plataforma mista e, posterior, substituição e progradação de uma plataforma carbonática.

Em um último estágio, já com a deposição do Cone Amazônico acima da plataforma carbonática, a qual ocorre de forma abrupta, percebe-se uma migração lateral de canais que geraram feições erosivas. É possível verificar este shift lateral do delta atual de sudeste para noroeste, ou seja, de A' para A. 
Discussão e Conclusões (Arial Bold, 9) 300

Segundo Vasconcellos (2012) é possível remontar a história evolutiva da bacia e contribuir com entendimento da mesma no sentido de criar novas expectativas exploratórias para seção pré-cone da Bacia da Foz do Amazonas. A presença de uma feição ígnea criou uma interessante estruturação na região destacada na Figura 2. Esta feição identificada na linha 0047-1067 afeta as sequências pré-rifte ( $F m$. Calçoene), rifte (formações Caciporé e Codó) e mesmo a sequência pósrifte (base da Formação Limoeiro). Fica claro que a feição ígnea identificada não é restrita à fase pré-rifte. No entanto, amostras datadas deste material magmático, amostrados no poço 1 APS 21 AP, indicam uma idade triássica (cerca de $200 \mathrm{Ma}$ ). Contudo, os pulsos observados no centro do corpo ígneo podem ser mais novos do que $200 \mathrm{Ma}$.; relacionados à reativações de falhas (Figura 4). Há também evidências que este evento vulcânico no mínimo afetou os carbonatos sobrejacentes, uma vez que falhas associadas à feição ígnea atingem os mesmos. Tal efeito pode estar associado à intumescência do local.

Distando cerca de $10 \mathrm{~km}$ da referida linha, o topo do poço 1APS 21 AP (Fugita, 2004) exibe deposição de dolomitas que poderiam estar associado a processos hidrotermais gerando assim melhores características de permo-porosidade. Uma possibilidade aqui levantada é que processos hidrotermais associados ao fim da ação do magmatismo podem gerar dolomitização dos carbonatos.

Concluiu-se que tal feição ígnea pode ter sido o substrato para a formação de uma plataforma mista (intercalação de siliciclásticos com carbonatos) que na bacia estaria representada pela Formação Limoeiro e, posteriormente, para a implantação da espessa plataforma carbonática Amapá. Esta feição ígnea criou grandes estruturas, que podem ser interessantes alvos exploratórios. Uma ferramenta útil para o reconhecimento dessas feições vulcânicas são os levantamentos magnetométricos e gravimétricos, como o levantamento EMAG2 utilizado pelo presente trabalho.

O embasamento da bacia foi interpretado apenas na linha 0047-1067. Nesta linha verificou-se uma grande intrusão ígnea que está relacionada a falhas que envolvem o embasamento de direção NW-SE, e constantes reativações de falhas transformantes de direção E-W, responsáveis pela separação das placas sul-americana e africana. Está linha sísmica corta a região de grabens alongados de direção NW-SE (grabens do Caciporé, Caciporezinho e Externo). Por fim, o mapa magnetométrico total mostrou uma feição bipolar característica de intrusões ígneas, sendo o mesmo importante para descartar por completo a possibilidade de argilocinese na região estudada.

\section{Agradecimentos}

As pessoas que de alguma forma contribuíram para este artigo. Em especial, aos geofísicos José Ribamar e André Rugenski que auxiliaram na área de métodos potenciais.

\section{Referências}

BRANDÃO, J. A. S. L.; FEIJÓ, F. J. Bacia da Foz do Amazonas. Boletim de Geociências da Petrobrás. Rio de Janeiro, v. 8, n. 1, p. 91-100, 1994.

FIGUEIREDO, J. J. P.; ZALAN ,P. V.; SOARES, E. F. Bacia da Foz do Amazonas. B. Geoci. Petrobras, Rio de Janeiro, v. 15, n. 2, p. 299-309, maio/nov. 2007.

FUGITA, A.M. Brasil Round 4: Foz do Amazonas Basin In: SEMINÁRIO JURÍDICO/FISCAL E WORKSHOP TÉCNICO DA QUARTA RODADA DE LICITAÇÕES. Disponível em: <http://www.anp.gov.br/brasilrounds/round4/round4/workshop/restrito/ingles/FozdoAm azonas ing.PDF> Acesso em: 20 dez. 2011.

VASCONCELLOS, R.V.A., 2012. Análise Estratigráfica do Campo de Pirapema na Bacia da Foz do Amazonas. Dissertação de Mestrado UERJ. Março de 2012. 

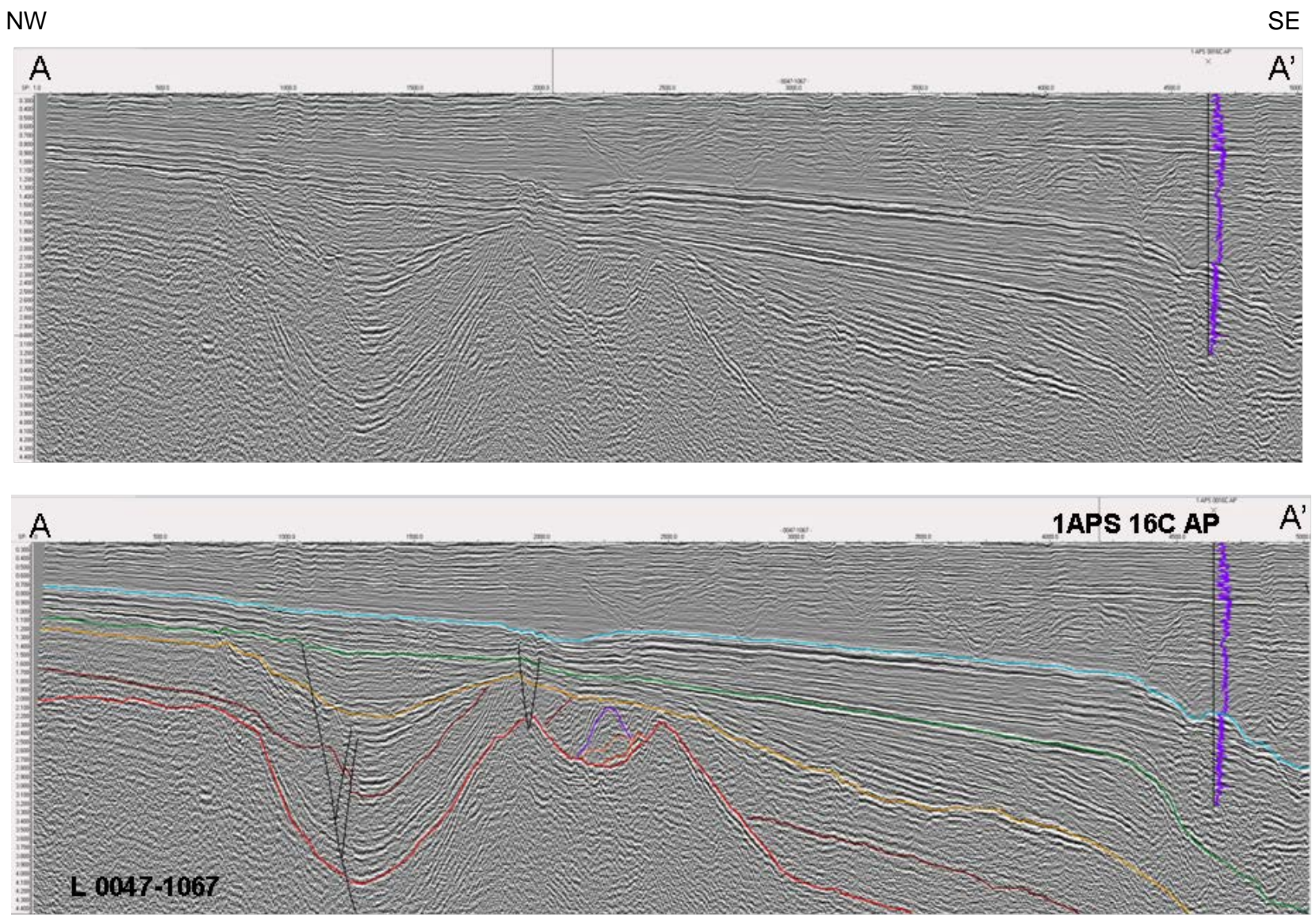

- Fm. Amapá
— Fm. Limoeiro
— Fm. Caciporé
— Fm. Calçoene
— Embasamento/Ígneas

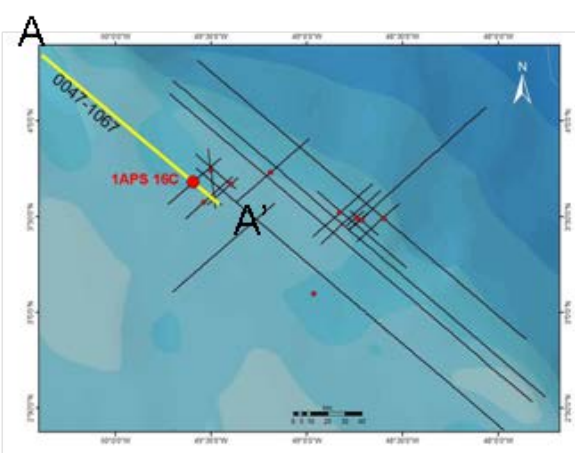

Figura 3 - Linha sísmica 0047-1067, apresentando as principais feições sedimentares, ígneas e estruturais. 

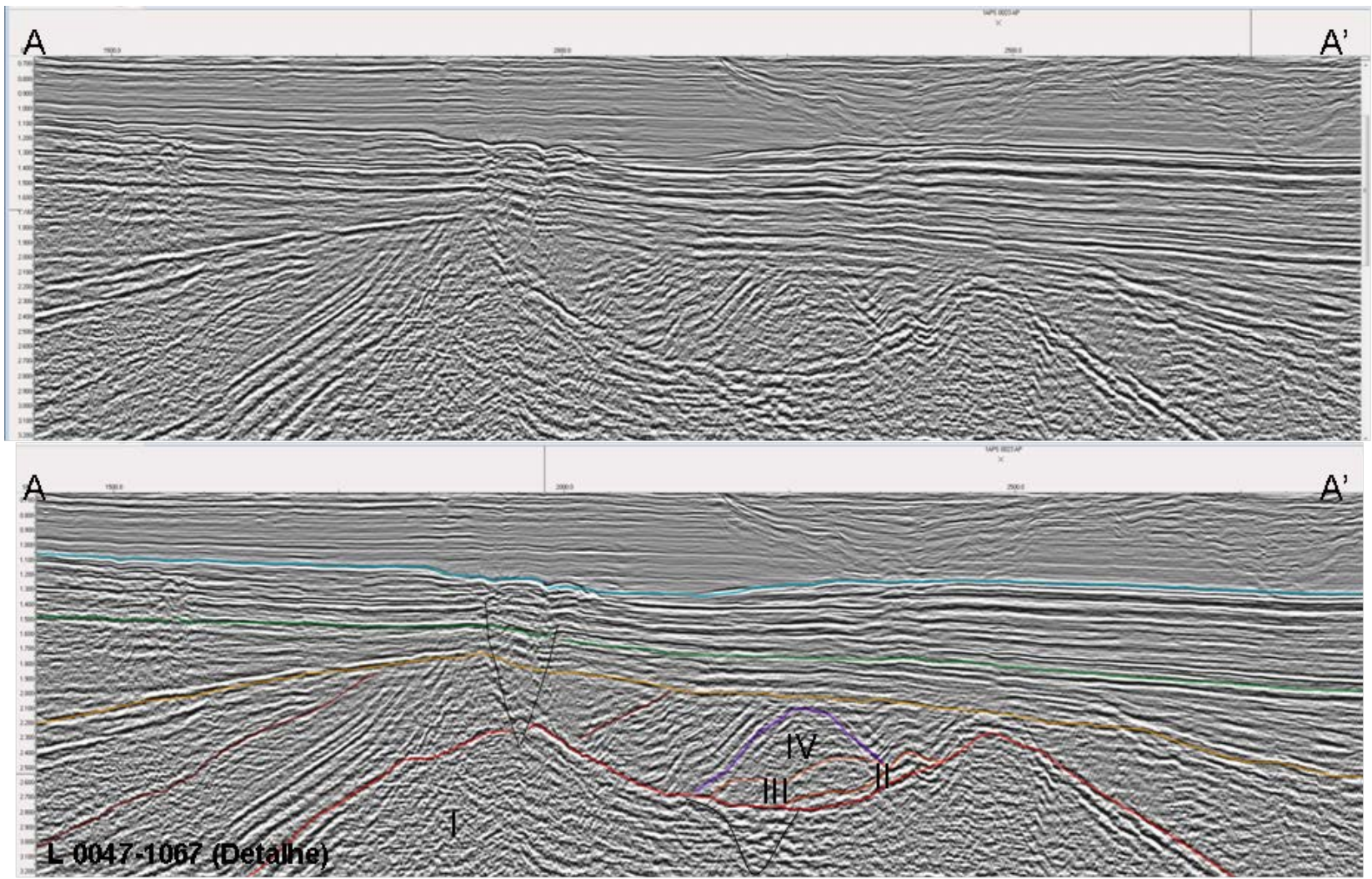

$\begin{array}{ll}\text { Fm. Amapá } & \text { - Ígnea I } \\ \text { — Fm. Limoeiro } & \text { - Ígnea II } \\ \text { — Fm. Caciporé } & \text { - Ígnea III } \\ \text { — Fm. Calçoene } & \text { - Ígnea IV }\end{array}$

Figura 4 - Detalhe da área de ocorrência das rochas ígneas na Linha sísmica 0047-1067. As feições marcadas em I, II, III e IV representam diferentes episódios magmáticos. 